\title{
The Effect of Hydrogen on the Nanoindentation Behavior of Heat Treated 718 Alloy
}

\author{
Gaute Stenerud $^{1}$, Tarlan Hajilou ${ }^{1, *} \mathbb{1}$, Jim Stian Olsen ${ }^{2,3}$, Iman Taji ${ }^{1}{ }^{\oplus}$, Afrooz Barnoush $^{1}$ \\ and Roy Johnsen ${ }^{1}$ \\ 1 Department of Mechanical and Industrial Engineering, Norwegian University of Science and Technology, \\ 7491 Trondheim, Norway; gautestenerud@gmail.com (G.S.); iman.taji@ntnu.no (I.T.); \\ afrooz.barnoush@ntnu.no (A.B.); roy.johnsen@ntnu.no (R.J.) \\ 2 Department of Structural Engineering, Norwegian University of Science and Technology, \\ 7491 Trondheim, Norway; Jim.Stian.Olsen@akersolutions.com \\ 3 Aker Solutions, No.1360 Fornebu, Oslo, Norway \\ * Correspondence: tarlan.hajilou@ntnu.no
}

Received: 8 September 2020; Accepted: 27 October 2020; Published: 30 October 2020

check for updates

\begin{abstract}
In this study, the effect of precipitates on the surface mechanical properties in the presence of hydrogen $(\mathrm{H})$ is investigated by in situ electrochemical nanoindentation. The nickel superalloy 718 is subjected to three different heat treatments, leading to different sizes of the precipitates: (i) solution annealing (SA) to eliminate all precipitates, (ii) the as-received (AR) sample with fine, dispersed precipitates, and (iii) the over-aged (OA) specimen with coarser precipitates. The nanoindentation is performed using a conical tip, and a new method of reverse imaging is employed to calculate the nano-hardness. The results show that the hardness of the SA sample is significantly affected by $\mathrm{H}$ diffusion. However, it could be recovered by removing the $\mathrm{H}$ from its matrix by applying an anodic potential. Since the precipitates in the OA and AR samples are different, they are influenced by $\mathrm{H}$ differently. The hardness increase for the OA sample is more significant in $-1200 \mathrm{mV}$, while for the AR specimen, the $\mathrm{H}$ is more effective in $-1500 \mathrm{mV}$. In addition, the pop-in load is reduced when the samples are exposed to cathodic charging, and it cannot be fully recovered by switching to an anodic potential.
\end{abstract}

Keywords: hydrogen embrittlement; superalloy 718; dislocation; nanoindentation; precipitates

\section{Introduction}

Nanoindentation is now a widely recognized technique that can probe a material's properties at the sub-micron scale. To determine the origin of damage or a failure in the structural components, it is necessary to distinguish the exact role of any microstructural parameter. It would be more complicated to understand the failure mechanism, when a complex microstructure is subjected to an environmental factor like hydrogen $(\mathrm{H})$. Nanoindentation, in the nano-meter scale, makes it possible to resolve specific parameters influencing the mechanical properties.

Ni-based super alloys gain their excellent mechanical properties from the nano-sized dispersed precipitates of $\gamma^{\prime}$ and $\gamma^{\prime \prime}$, which are embedded in the $\gamma$ matrix. The cubic $\left(L 1_{2}\right) \gamma^{\prime}$ precipitates have a $\mathrm{Ni}_{3}(\mathrm{Al}, \mathrm{Ti})$ chemical composition. The $\gamma^{\prime \prime}$ precipitates $\left(\mathrm{Ni}_{3}(\mathrm{Nb})\right)$ have a tetragonal $\left(\mathrm{DO}_{22}\right)$ crystal microstructure, which can transform to a more stable $\delta$ phase $\left(\mathrm{DO}_{a}\right)$ under thermomechanical processes. It is reported that when the $\mathrm{Al}: \mathrm{Nb}$ ratio is lower than $0.3, \gamma^{\prime \prime}$ would be the preferential precipitates in the matrix [1,2]. Generally, the formation of the precipitates is accompanied by a misfit strain due to the lattice mismatch of the precipitate-matrix atoms. During deformation, dislocations can accommodate around the precipitates. This interfacial dislocation network later on plays a role in the alloy's strength enhancement. On the other hand, they can be favorable trapping sites for the $\mathrm{H}$ atoms. The shape and 
the interface coherency of the precipitates strongly depend on the aging condition. Aging samples at higher temperatures or for a longer time than the conventional condition could lead to a higher level of interface misfit strain or even coherency breaking [3,4]. By increasing the interfacial misfit, the bonding energy with $\mathrm{H}$ increases, which means higher activation energy is needed for trapping of $\mathrm{H}$ atoms [5]. In this study, the effect of the H-precipitation interaction, obtained by different aging treatments, is investigated by the nanoindentation technique.

\section{Materials and Methods}

Ni-based superalloy 718 with the main alloying elements of Fe:18.64, Cr:17.64, Nb:5.35, Mo:2.88, Ti:1:00, and Al:0.53 was used in this study. To evaluate the effect of precipitates on hydrogen embrittlement resistance, three different heat treatment conditions were used as described in Table 1 . The average ASTM grain size of the solution annealed (SA), as-received (AR), and over-aged (OA) samples was measured as 872,95 , and $895 \mu \mathrm{m}$, respectively. The smaller grain size of the AR sample is a result of the thermo-mechanical process applied during manufacturing.

Table 1. A summary of the different heat treatments applied to the Ni-based superalloy 718 used in this study.

\begin{tabular}{ll}
\hline Material Condition & Heat Treatment \\
\hline Solution annealed (SA) & Solution annealing at $1200^{\circ} \mathrm{C}, 2 \mathrm{~h} /$ water quenching \\
\hline As received (AR) & $\begin{array}{l}\text { Solution annealing at } 1200^{\circ} \mathrm{C}, 2 \mathrm{~h} / \text { water quenching, thermomechanical treatment } \\
\text { and age-hardening at } 720 \text { and } 620^{\circ} \mathrm{C}, 8+8 \mathrm{~h} / \text { air cooling }\end{array}$ \\
\hline Over-aged (OA) & $\begin{array}{l}\text { Solution annealing at } 1200{ }^{\circ} \mathrm{C}, 2 \mathrm{~h} / \text { water quenching, over-aging at } 800^{\circ} \mathrm{C}, \\
8 \mathrm{~h} / \text { water quenching }\end{array}$ \\
\hline
\end{tabular}

The available precipitates in the microstructure, which was resolved using JEOL JEM-2100F transmission electron microscopy, are presented in Figure 1. The SA treatment ends up with almost no precipitation, while the OA sample possesses coarser precipitates compared to the fine precipitates in the AR specimen.
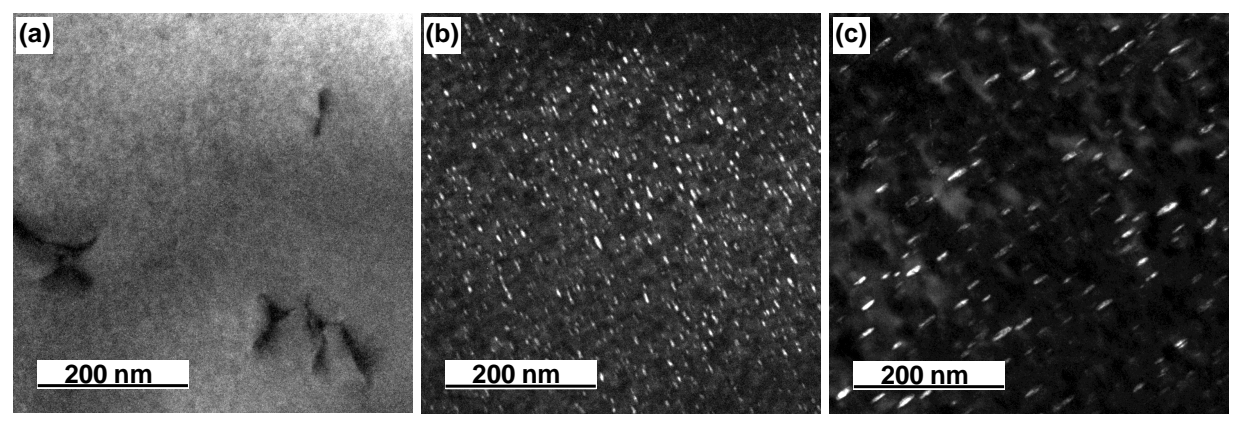

Figure 1. Dark field TEM micrographs showing the precipitation distribution in the (a) SA, (b) AR, and (c) OA samples.

The specimen's surface was prepared by grinding and mechanical polishing followed by electrochemical polishing using a $1 \mathrm{M}$ methanolic $\mathrm{H}_{2} \mathrm{SO}_{4}$ solution. To eliminate the crystallographic orientation dependency, a similar grain orientation of $\{101\}$ was selected according to the orientation imaging map (OIM) of the samples. In situ electrochemical nanoindentation was performed using the Bruker TI 950 TriboIndenter system, which was integrated with a custom, three electrode miniaturized electrochemical cell [6]. The electrochemical setup consisted of counter, working, and $\mathrm{Hg} / \mathrm{HgSO}_{4}$ reference electrodes. All reported potentials are versus this reference electrode. The hydrogen charging electrolyte was a mixture of glycerol/phosphoric acid with a proportion of 2/1. Nanoindentation was performed in a $\mathrm{H}$-free condition in an air atmosphere as the reference data. Afterwards, samples were polarized galvanostatically at two current densities of 0.32 and $2.3 \mathrm{~mA} / \mathrm{cm}^{2}$ for $1 \mathrm{~h}$, equivalent to potentials of -1200 
and $-1500 \mathrm{mV}$, respectively. After each switch between cathodic current densities, the samples were polarized anodically at $600 \mathrm{mV}$ for $1 \mathrm{~h}$ to extract the absorbed $\mathrm{H}$ charged to the subsurface. The selected grain for nanoindentation was large enough to accommodate 25 indents $\times 5$ testing conditions using a $90^{\circ}$ conical tip with a nominal tip radius of $1 \mu \mathrm{m}$. The space between each indent was $5 \mu \mathrm{m}$ to avoid the interference of the indentation influenced area between subsequent indents. The load function was designed with a maximum load of $2500 \mu \mathrm{N}$ with an $8000 \mu \mathrm{N} / \mathrm{s}$ loading rate.

\section{Results and Discussion}

\subsection{Hardness Measurement}

The rotation of the Berkovich tip or the testing grain around the loading axis has been reported to affect the nano-hardness [7]. Therefore, a conical tip was used for nanoindentation to rule out this intrinsic anisotropic effect. The hardness is calculated by $H=\frac{P_{\max }}{A_{c}}$ where $P_{\max }$ is the maximum load in the load function. Conventionally, the projected contact area $\left(A_{c}\right)$ can be calculated as $A_{c}=\pi h_{c}^{2} \tan ^{2} \alpha$ using an ideal asymmetric conical tip, where $h_{c}$, the contact depth, is calculated by:

$$
h_{c}=h_{\max }-0.75 \frac{P_{\max }}{S}
$$

Here, $h_{\max }$ is the displacement at maximum load and $S$ is the contact stiffness. Due to either the manufacturing process or repetitive use of the tip, the tip apex shape deviates from its ideal shape. Therefore, the area function calibration is needed to measure the correct hardness. The basic calculation of $A_{c}$ for a conical tip is based on the assumption that the tip has a spherical apex, which is attached with a $\alpha$ angle to a cone. To eliminate the non-ideal shape effect, in this study, the real shape of the tip is used for hardness calculation. Figure 2a shows the tip image obtained by scanning probe microscopy of the nanoindenter on the commercial calibration sample. This sample has needles with a distance of $3 \mu \mathrm{m}$, which is used here for reverse imaging of the tip. Having the real shape of the indenter, it is straight forward to calculate the hardness by getting the $h_{c}$ from the load-displacement (L-D) curve and measuring the related $A_{c}$ from the tip image in the given $h_{c}$. In Figure $2 \mathrm{~b}$, the circled points show the cross-section of the conical tip at three representative $h_{c}$ obtained by the nanoindentation. As can be seen, the projected area of the cross-section forms an elliptical shape with the surface area of $A_{c}$.

(a)

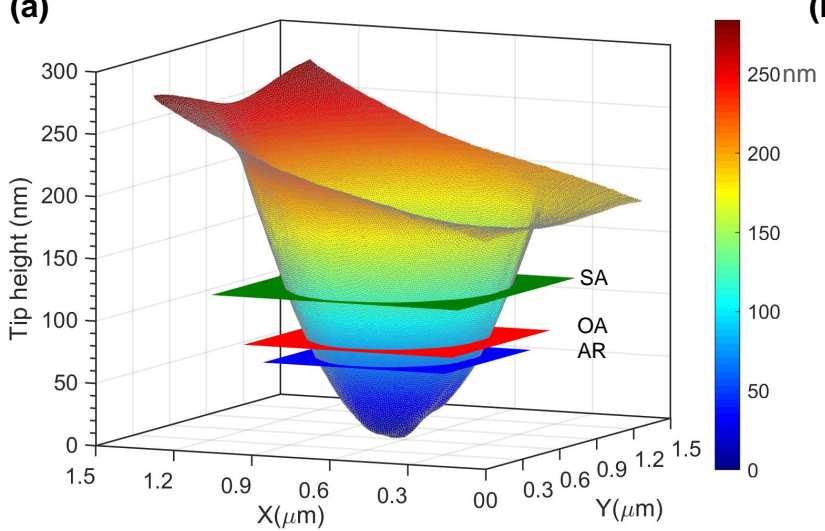

(b)

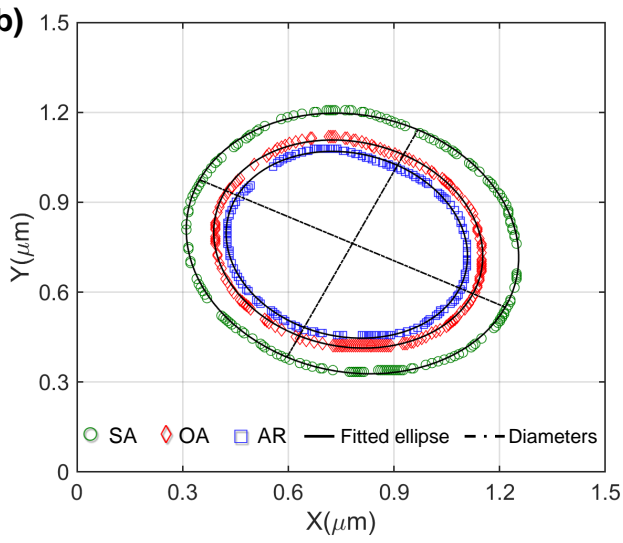

Figure 2. (a) The 3D conical tip topography obtained by reverse imaging. The three planes crossing the tip show a representative $h_{c}$ for the SA, OA, and AR samples obtained from the nanoindentation L-D curves. (b) The cross-sectional top view of the three mentioned planes fit with an elliptical shape.

\subsection{Precipitation Effect on Hardness and Plasticity Onset}

Figure 3 summarizes the hardness and pop-in (plasticity onset) values in different testing conditions for the three heat treated samples. As expected, the SA sample, with no precipitates, 
shows the lowest hardness. For the two aged conditions, the hardness increases as the precipitate size decreases.
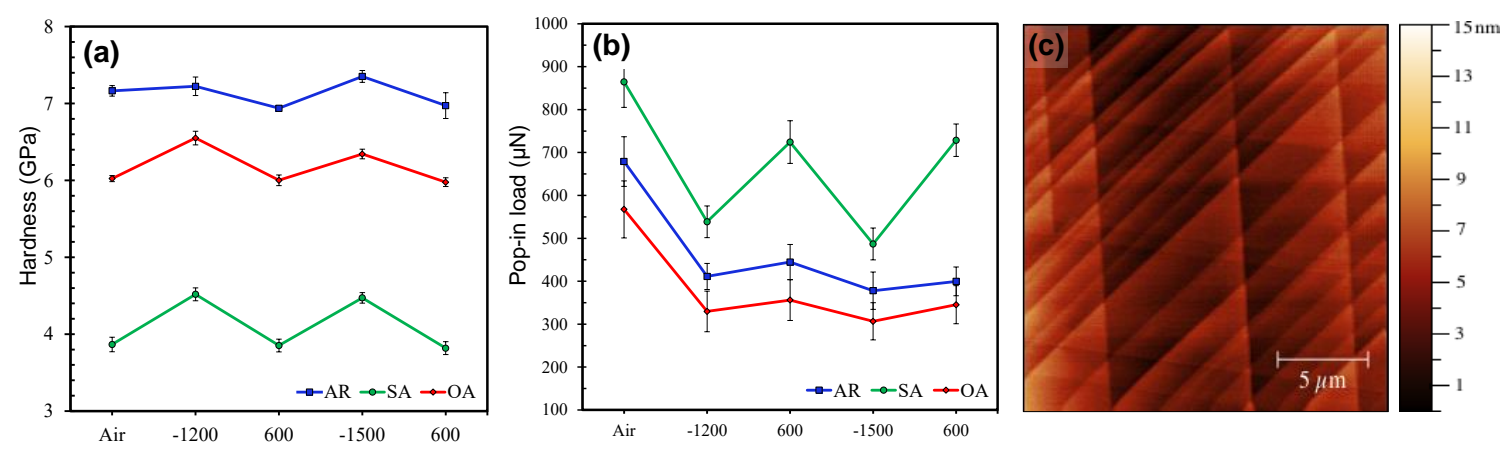

Figure 3. Averaged (a) hardness and (b) pop-in load values for the three heat treated samples in air and under different applied potentials obtained by nanoindentation. (c) Surface topography of the SA sample after exposure to $-1500 \mathrm{mV}$ for $1 \mathrm{~h}$.

Generally, exposing the material to the cathodic condition and introducing atomic $\mathrm{H}$ into the subsurface would result in a hardness increase. Anodic discharging of the sample, on the other hand, would extract the dissolved $\mathrm{H}$ and recover the hardness to the non-charged condition. For the SA sample case, $\mathrm{H}$ ingress into the matrix of the alloy facilitates the dislocation nucleation, leading to higher dislocation density in the activated volume below the tip. Using the in situ electrochemical nanoindentation method, it has been shown that the activation energy for the onset of plasticity (dislocation nucleation) is reduced by dissolved hydrogen, which was explained in detail in ref. [8]. The defectant theory proposed by Kirchheim [9] based on thermodynamics calculations also provides a theoretical basis for the reduction of the dislocation formation energy in the presence of $\mathrm{H}$ segregation. On the other hand, $\mathrm{H}$ is reported to suppress the dislocation movement $[10,11]$. High dislocation density formed beneath the indenter tip along with the $\mathrm{H}$ suppression effect holds the formed dislocations in a confined area beneath the indent, resulting in the hardness enhancement. In addition, since the SA sample is water quenched from $1200^{\circ} \mathrm{C}$, it is expected to have a high vacancy concentration. During electrochemical $\mathrm{H}$ charging, vacancy-H cluster formation can also have a contribution to the observed hardness increase [12].

For both aged samples, the increase in the hardness by adding $\mathrm{H}$ to the system is lower comparing to the SA sample. This phenomenon can be explained considering the role of the precipitates. The precipitates can act as a trap for $\mathrm{H}$, decreasing the available $\mathrm{H}$ in the nearby matrix. However, the hardness enhancement by aging treatment differs between the AR and OA samples. At $-1200 \mathrm{mV}$, the AR sample hardness does not show a significant increase, while there is approximately a $9 \%$ increase for the OA sample. Due to the higher coherency of the smaller precipitates in the AR sample, more $\mathrm{H}$ can be trapped in either the interface or the precipitate [5]. Therefore, compared to the OA sample, the AR sample will have a lower amount of $\mathrm{H}$ present in the matrix around the precipitates, providing a lower effect on the nano-hardness. At $-1500 \mathrm{mV}$, however, the higher concentration of $\mathrm{H}$ ingress into the material would be enough to increase the hardness by raising the matrix $\mathrm{H}$ concentration. On the contrary, in the OA sample, shifting the potential to $-1500 \mathrm{mV}$ resulted in a lower increase in the hardness compared to $-1200 \mathrm{mV}$. In this case, the higher H concentration can overcome the higher binding energy of the coarser precipitates with a higher lattice misfit. At $-1200 \mathrm{mV}$, hydrogen's chemical potential cannot overcome the interface binding energy, and $\mathrm{H}$ atoms mostly disperse in the matrix. At $-1500 \mathrm{mV}$, due to the higher chemical potential, $\mathrm{H}$ atoms gain energy to be trapped in precipitates, which results in the depletion of $\mathrm{H}$ in the nearby lattice around the precipitates.

The effect of the precipitates and the $\mathrm{H}$ on the pop-in load is depicted in Figure $3 \mathrm{~b}$. The pop-in in the L-D curve of the nanoindentation is mainly attributed to the homogeneous dislocation nucleation underneath the tip. Cathodic polarization of the samples, generally, decreases the pop-in load. 
The observed reduction in the pop-in load with $\mathrm{H}$ can be explained by the reduction of the required energy for the dislocation nucleation [9]. The pop-in loads in the aged samples, compared to the SA one, show lower values. These lower values indicate that the onset of plasticity or dislocation nucleation is more feasible in aged samples, which is rationalized by molecular dynamics simulation of the nickel-based superalloy. This research shows that the matrix-precipitate interface could act as the dislocation nucleation sites [13]. Indeed, lattice misfit between the matrix and the precipitate reduces the required energy for the dislocation nucleation.

Another point in Figure $3 \mathrm{~b}$ is that $\mathrm{H}$ degassing by anodic polarization did not recover the pop-in load to the original value in the air condition. For materials with high $\mathrm{H}$ solubility, $\mathrm{H}$ ingress can generate permanent subsurface defects, which increase the material's dislocation density. For example, in the SA sample, the high sub-surface $\mathrm{H}$ concentration produces internal stress, which leads to dislocation nucleation and their movement towards the surface. Figure $3 \mathrm{c}$ shows the slip lines formed on the SA surface due to $\mathrm{H}$ induced internal stress. As a result, under anodic polarization where the diffused $\mathrm{H}$ egresses, the increased defect density remaining in the material results in lower pop-in load compared to the uncharged condition.

\section{Conclusions}

This study evaluates the effect of precipitates on the nano-hardness and plasticity burst in the presence of electrochemical $\mathrm{H}$ charging. The main conclusions are as follow:

1. A new method is employed to obtain the $A_{c}$ of the nanoindentation directly from the tip image to calculate the hardness value.

2. While the precipitates in the matrix increase the hardness significantly, compared to the SA sample, aged samples are less affected by $\mathrm{H}$ charging.

3. Hardness enhancement of the OA sample is higher at $-1200 \mathrm{mV}$, whereas the $-1500 \mathrm{mV}$ cathodic polarization is more effective for the hardness increase of the AR sample. The possible reasons are explained based on the interaction of $\mathrm{H}$, the matrix, and precipitations.

4. Cathodic polarization decreases the pop-in load, which cannot be fully recovered under the anodic $\mathrm{H}$ egression.

Author Contributions: Conceptualization, A.B. and R.J.; methodology, G.S. and T.H.; software, T.H.; formal analysis, G.S. and T.H.; data curation, G.S. and T.H.; writing, original draft preparation, G.S., T.H., I.T., and J.S.O.; writing, review and editing, G.S., T.H., I.T., J.S.O., A.B., and R.J.; supervision, J.S.O., A.B., and R.J. All authors read and agreed to the published version of the manuscript.

Funding: This research was funded by Aker Solution and NTNU.

Acknowledgments: Sigurd Wenner from the Department of Physics, NTNU, is acknowledged for contributing the TEM images.

Conflicts of Interest: The authors declare no conflict of interest.

\section{Abbreviations}

The following abbreviations are used in this manuscript:

$\mathrm{H}$ Hydrogen

SA Solution annealed

AR As-received

OA Over-aged

$A_{c} \quad$ Projected contact area

L-D Load-displacement 


\section{References}

1. Mignanelli, P.M.; Jones, N.G.; Pickering, E.J.; Messé, O.M.D.M.; Rae, C.M.F.; Hardy, M.C.; Stone, H.J. Gamma-gamma prime-gamma double prime dual-superlattice superalloys. Scr. Mater. 2017, 136, $136-140$. [CrossRef]

2. Slama, C.; Abdellaoui, M. Structural characterization of the aged Inconel 718. J. Alloys Compd. 2000, 306, 277-284. [CrossRef]

3. Yoo, Y.; Yoon, D.; Henry, M. The effect of elastic misfit strain on the morphological evolution of $\gamma^{\prime}$-precipitates in a model Ni-base superalloy. Met. Mater. 1995, 1, 47-61.

4. Zhang, R.Y.; Qin, H.L.; Bi, Z.N.; Li, J.; Paul, S.; Lee, T.L.; Zhang, S.Y.; Zhang, J.; Dong, H.B. Temperature-Dependent Misfit Stress in Gamma Double Prime Strengthened Ni-Base Superalloys. Metall. Mater. Trans. A 2020, 51, 1860-1873. [CrossRef]

5. Zhang, Z.; Moore, K.L.; McMahon, G.; Morana, R.; Preuss, M. On the role of precipitates in hydrogen trapping and hydrogen embrittlement of a nickel-based superalloy. Corros. Sci. 2018, 146, 58-69. [CrossRef]

6. Hajilou, T.; Deng, Y.; Kheradmand, N.; Barnoush, A. Hydrogen enhanced cracking studies on Fe-3wt $\% \mathrm{Si}$ single and bi-crystal microcantilevers. Philos. Trans. R. Soc. A Math. Phys. Eng. Sci. 2017, 375, 20160410. [CrossRef] [PubMed]

7. Jakob, S.; Leitner, A.; Lorich, A.; Eidenberger-Schober, M.; Knabl, W.; Pippan, R.; Clemens, H.; Maier-Kiener, V. Influence of crystal orientation and Berkovich tip rotation on the mechanical characterization of grain boundaries in molybdenum. Mater. Des. 2019, 182, 107998. [CrossRef]

8. Barnoush, A.; Vehoff, H. In situ electrochemical nanoindentation: A technique for local examination of hydrogen embrittlement. Corros. Sci. 2008, 50, 259-267. [CrossRef]

9. Kirchheim, R. Reducing grain boundary, dislocation line and vacancy formation energies by solute segregation. I. Theoretical background. Acta Mater. 2007, 55, 5129-5138. [CrossRef]

10. Wan, D.; Deng, Y.; Meling, J.I.H.; Alvaro, A.; Barnoush, A. Hydrogen-enhanced fatigue crack growth in a single-edge notched tensile specimen under in situ hydrogen charging inside an environmental scanning electron microscope. Acta Mater. 2019, 170, 87-99. [CrossRef]

11. Ogawa, Y.; Birenis, D.; Matsunaga, H.; Thøgersen, A.; Prytz, Ø.; Takakuwa, O.; Yamabe, J. Multi-scale observation of hydrogen-induced, localized plastic deformation in fatigue-crack propagation in a pure iron. Scr. Mater. 2017, 140, 13-17. [CrossRef]

12. Metsue, A.; Oudriss, A.; Feaugas, X. Trapping/detrapping kinetic rates of hydrogen around a vacancy in nickel and some consequences on the hydrogen-vacancy clusters thermodynamic equilibrium. Comput. Mater. Sci. 2018, 151, 144-152. [CrossRef]

13. Yashiro, K.; Naito, M.; Tomita, Y. Molecular dynamics simulation of dislocation nucleation and motion at $\gamma / \gamma^{\prime}$ interface in Ni-based superalloy. Int. J. Mech. Sci. 2002, 44, 1845-1860. [CrossRef]

Publisher's Note: MDPI stays neutral with regard to jurisdictional claims in published maps and institutional affiliations.

(C) 2020 by the authors. Licensee MDPI, Basel, Switzerland. This article is an open access article distributed under the terms and conditions of the Creative Commons Attribution (CC BY) license (http:/ / creativecommons.org/licenses/by/4.0/). 